\title{
Antibodies to Lactobacilli and Bifidobacteria in Young Children with Different Propensity to Develop Islet Autoimmunity
}

\author{
Ija Talja, ${ }^{1}$ Anna-Liisa Kubo, ${ }^{1}$ Riitta Veijola, ${ }^{2}$ Mikael Knip, ${ }^{3,4,5}$ Olli Simell, ${ }^{6}$ Jorma Ilonen, ${ }^{7,8}$ \\ Mari Vähä-Mäkilä, ${ }^{6}$ Epp Sepp, ${ }^{9,10}$ Marika Mikelsaar, ${ }^{9,10}$ Meeme Utt, ${ }^{1,10}$ and Raivo Uibo ${ }^{1,10}$ \\ ${ }^{1}$ Immunology Group, Institute of Biomedicine and Translational Medicine, University of Tartu, Ravila 19, 50411 Tartu, Estonia \\ ${ }^{2}$ Department of Pediatrics, University of Oulu, Kajaanintie 50, 90014 Oulu, Finland \\ ${ }^{3}$ Children's Hospital, University of Helsinki and Helsinki University Central Hospital, Tukholmankatu 8 A, 00029 Helsinki, Finland \\ ${ }^{4}$ Department of Pediatrics, Tampere University Hospital, Teiskontie 35, 33521 Tampere, Finland \\ ${ }^{5}$ Folkhälsan Research Center, Haartmansg 8, 00290 Helsinki, Finland \\ ${ }^{6}$ Department of Pediatrics, University of Turku, 20014 Turku, Finland \\ ${ }^{7}$ Immunogenetics Laboratory, University of Turku, 20014 Turku, Finland \\ ${ }^{8}$ University of Eastern Finland, Yliopistonranta 1, 70211 Kuopio, Finland \\ ${ }^{9}$ Department of Microbiology, University of Tartu, Ravila 19, 50411 Tartu, Estonia \\ ${ }^{10}$ Centre for Translational Medicine, University of Tartu, Ravila 19, 50411 Tartu, Estonia
}

Correspondence should be addressed to Raivo Uibo; raivo.uibo@ut.ee

Received 18 November 2013; Revised 16 January 2014; Accepted 20 January 2014; Published 4 March 2014

Academic Editor: Jacek Tabarkiewicz

Copyright (c) 2014 Ija Talja et al. This is an open access article distributed under the Creative Commons Attribution License, which permits unrestricted use, distribution, and reproduction in any medium, provided the original work is properly cited.

\begin{abstract}
The intestinal microbiota is essential to the maturation and homeostasis of the immune system. Immunoblot assays were used to establish the prevalence of serum IgG, IgM, and IgA antibodies specific for Bifidobacterium adolescentis, Bifidobacterium longum, and Lactobacillus rhamnosus GG proteins in young children presenting with or without type 1 diabetes (T1D). We demonstrated that children between the ages of 6 and 12 months had a substantial increase in the frequency of IgG antibodies specific for $L$. rhamnosus GG proteins. We measured IgG, IgM, and IgA class antibody reactivity against B. adolescentis DSM 20083, B. adolescentis DSM 20086, and B. longum DSM 20088 proteins demonstrating significantly higher IgA responses against B. adolescentis DSM 20083 strain proteins in children who developed islet autoimmunity and T1D later in life. B. adolescentis strains showed more IgM type antibodies in children who developed T1D later in life, but the difference was not statistically significant. B. longum proteins were recognized by IgG and IgA antibodies to a higher extent compared to other bacteria studied. These results confirm that differences in immune reactivity against some commensal strains in young children may represent a different risk factor for developing T1D.
\end{abstract}

\section{Introduction}

Type 1 diabetes (T1D) is characterized by immune-mediated destruction of the insulin-secreting $\beta$ cells in the pancreatic islets as a result of an unknown trigger mechanism. It is, however, well known that development of clinical disease is preceded by an asymptomatic latent period during which immune reactions against the insulin-secreting cell autoantigens can be demonstrated [1-3]. In this context, biochemically detectable autoantibodies against insulin (IAA), glutamic acid decarboxylase (GADA), insulinoma-associated antigen 2 (IA-2A), and Zn-transporter 8 (ZnT8A) as well as their counterpart immunofluorescent anti-islet antibodies (ICA) serve as reliable biomarkers for T1D development. Specifically, Knip et al. [3] demonstrated that all children initially testing positive for both GADA and IA-2A progressed to clinical T1D over a 26-year followup.

Over the last few decades the incidence of T1D has dramatically increased in many countries particularly in early childhood, suggesting that an event associated with progression towards T1D disease was occurring early in life. An increasing number of studies have suggested that the composition of the intestinal microbiota might contribute significantly to the development of disorders such as TID since 
changes to the microflora mirror changes in general life styles and the social system [4-6].

It is believed that intestinal colonization with certain bacteria strongly influences systemic immune responses early in life and may play a significant role in modulating the development of various chronic diseases [7]. Some of the most common constituents of the gastrointestinal tract microbiota include Bifidobacterium and Lactobacillus species that have been shown to play a significant role in the development of immune-mediated disorders in humans [8-11]. That is, predominant colonization with $B$. adolescentis has been reported in patients with allergic disorders compared to colonization patterns observed in individuals with nonallergic disorders [12-14]. Other Bifidobacterium species have been shown to have diverse effects, including variable associations of $B$. longum with immune-mediated and inflammatory diseases. Studies of rodent disease models $[15,16]$ have also identified differences in the ability of different Bifidobacterium species in modulating immune reactivity and inflammation. These observations are in line with study results showing that different Lactobacillus spp. may have diverse immunomodulating effects on different diseases [17]. Most well known are the effects of the probiotic strain L. rhamnosus GG in preventing atopic eczema among infants, possibly by modulating the immune response to allergens [18]. The recent identification of the L. rhamnosus GG p40 molecule as an immunomodulator [19] represents a significant step forward towards resolving problems related to the effects of probiotics in vivo.

Previously we demonstrated that the elicitation of antibodies against $L$. acidophilus antigenic components differed between children with various chronic diseases [20]. The current study describes experiments designed to extend these observations by investigating the prevalence of serum antibodies against $B$. adolescentis, $B$. longum, and L. rhamnosus GG in young children that developed or did not develop T1D.

\section{Material and Methods}

2.1. Plasma Samples. Plasma samples $(n=107)$ from 38 children participating in the Finnish Type 1 Diabetes Prediction and Prevention (DIPP) study and born between 1995 and 2003 were included in this study. Children were separated into 2 groups of 19 children (11 females) each matched for age and sex. One group was comprised of children who later developed at least 2 T1D-related autoantibodies and subsequently clinical T1D (islet autoimmunity [IA], i.e., the IA-positive group) and the other group was comprised of children that did not develop or present with signs of islet autoimmunity (IA-negative group) and without T1D during followup. Islet autoimmunity was defined in this context as detection of at least 2 antibodies out of GADA (assay sensitivity $82 \%$, specificity $96 \%$ ), IA-2A (assay sensitivity $72 \%$, specificity 100\%), and/or ICA. Levels of ICA were measured by an indirect immunofluorescence assay with a detection limit of 2.5 Juvenile Diabetes Foundation Units. All children in the IA-positive group later developed T1D (age at onset ranged between 2.4 and 10.3 years). Both groups were similar in their documented use of antibiotics (during the first 2 years of life 13/18 IA-positive children and 17/18 IA-negative children were treated with antibiotics; $P=0.177$; the data pertaining to one child from each group was not available). No differences in the use of probiotics between groups were observed ( 2 children from the IA-positive group; $P=$ 0.487).

2.2. Bacterial Strains and Cell Lysate Preparation. WilkinsChalgren agar (Oxoid, UK) was used to culture B. adolescentis DSM 20083 (ATCC 15703) and DSM 20086 (ATCC 15705) and B. longum DSM 20088 (ATCC 15697). Man-RogosaSharpe agar (Oxoid, UK) was used to culture L. rhamnosus GG. Wilkins-Chalgren agar plates were incubated in an anaerobic cabinet (Concept, UK; with gas mixture of $5 \%$ $\mathrm{CO}_{2}, 5 \% \mathrm{H}_{2}$, and $90 \% \mathrm{~N}_{2}$ ) and Man-Rogosa-Sharpe agar in a microaerobic environment (Joan, France) with a gas mixture of $10 \% \mathrm{CO}_{2}$ for $48 \mathrm{~h}$.

Bacterial cells were collected, suspended in phosphatebuffered saline solution (PBS, $\mathrm{pH}=7.4$ ), and washed 3 times with the same buffer. Subsequently, cells were disrupted with $0.1 \mathrm{~mm}$ glass beads (Biospec Products, USA) in PBS in the presence of complete protease inhibitors (Boehringen Mannheim-Roche, Switzerland) on ice. The total protein concentration in lysates was determined using the Protein Assay solution (Bio-Rad, USA) using bovine serum albumin as a standard and kept in aliquots at $-20^{\circ} \mathrm{C}$ until used.

\subsection{Gradient Sodium Dodecyl Sulphate Polyacrylamide Gel} Electrophoresis (SDS-PAGE) and $1 D$ Immunoblotting. Equal amounts of proteins from different Bifidobacteria spp. preparations were mixed with $300 \mu \mathrm{L}$ SDS-PAGE sample buffer and heated for $15 \mathrm{~min}$ at $95^{\circ} \mathrm{C}$. To each gel approximately $100 \mu \mathrm{g}$ of protein was loaded.

The proteins in the bacterial cell lysate were loaded on a $5-20 \%$ gradient gel with a $5 \%$ concentrating gel with All Blue $10-250 \mathrm{kDa}$ molecular weight (MW) markers (BioRad, USA) as standards and separated by electrophoresis using a current of $40 \mathrm{~mA}$ and a voltage of $200 \mathrm{~V}$ for $6 \mathrm{~h}$ using a vertical electrophoresis system SE-600 (Hoefer, USA) connected to a thermostatic circulator. Separated proteins were transferred onto a polyvinylidene difluoride (PVDF) membrane ( $0.45 \mu \mathrm{m}$ pore size) using a semidry electroblotter (Hoefer, USA) at a current density of $1 \mathrm{~mA} / \mathrm{cm}^{2}$ for $1.5 \mathrm{~h}$ and membranes blocked as described by Nilsson et al. [21].

Five $\mathrm{mm}$ wide strips were cut from the membrane and incubated with plasma samples diluted to 1:50 for IgA and IgM and 1:100 for IgG in the incubating buffer [21] overnight at $4^{\circ} \mathrm{C}$. Strips were then incubated with either secondary anti-human IgA, anti-human IgM, or anti-human IgG antibodies labelled with horse-radish peroxidase (HRP) (diluted 1:500; Dako, Denmark) for 1h and subsequently developed in substrate solution comprised of $0.04 \%$ carbazole in $50 \mathrm{mM}$ sodium acetate buffer $(\mathrm{pH}=5.0)$ and hydrogen peroxide $(0.015 \%)$ for $30 \mathrm{~min}$ at room temperature. All serum samples were screened in similar fashion. The strips were scanned using a Bio-Rad GS-710 Imaging densitometer (BioRad, USA). The relative MW of the bands was estimated with 


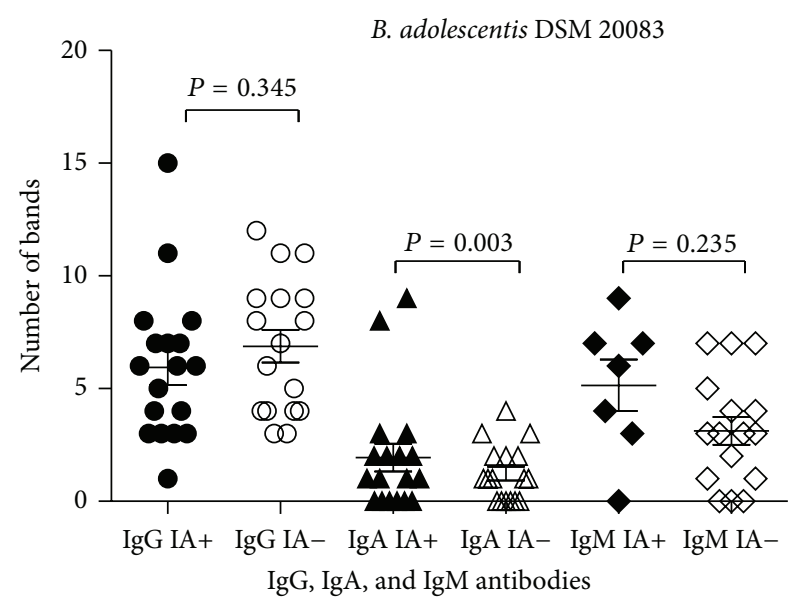

Figure 1: IgG, IgA, and IgM reactivity to B. adolescentis DSM 20083 proteins among IA-positive and IA-negative individuals.

the Bio-Rad Quantity One image analysis software (Bio-Rad, USA) according to the All Blue molecular weight markers.

2.4. Statistical Analysis. The F-test was used to compare the frequency of antibodies in the two groups. $P$ values below 0.05 were considered statistically significant.

\section{Results}

3.1. IgG Antibody Reactivity to L. rhamnosus GG Proteins. We first analyzed the dynamics of IgG antibodies that developed against $L$. rhamnosus $\mathrm{GG}$ target antigens in children between 3 and 24 months of age. This approach was chosen due to the frequent consumption of the probiotic L. rhamnosus GGcontaining dairy products by children and adults in Finland. We discovered 25 clearly distinguishable $L$. rhamnosus GG antigenic proteins ranging between 11 and $86 \mathrm{kDa}$ (Table 1). The number of L. rhamnosus GG proteins recognized by IgG increased steadily with age. Table 2 describes the 9 most frequently reactive proteins. Children between the ages of 12 and 24 months presented with significantly more antibodies against $5 / 9(31,42,45,47$, and $49 \mathrm{kDa}$ proteins) selected highly reactive proteins compared to reactivity observed in 3 -month-old infants. However, no significant differences in IgG reactivity were observed in response to L. rhamnosus GG antigens between IA-positive and IA-negative children.

The average number of IgG-reactive L. rhamnosus GG protein bands was $10.5 \pm 6.6$ in IA-positive infants (between 5 and 17 bands) and $11.5 \pm 7.2$ in IA-negative children (between 5 and 20 bands) at 12 months of age. Based on these results the 12-month-old group was chosen for further analysis of immune reactivity against Bifidobacterium spp. antigens.

3.2. IgG Reactivity against B. adolescentis and B. longum Proteins. IgG bound to Bifidobacterium antigens in the molecular weight ranging from $7 \mathrm{kDa}$ to $131 \mathrm{kDa}$. The number of proteins recognized varied between strains with the greatest number of reactive antigens observed for B. longum DSM

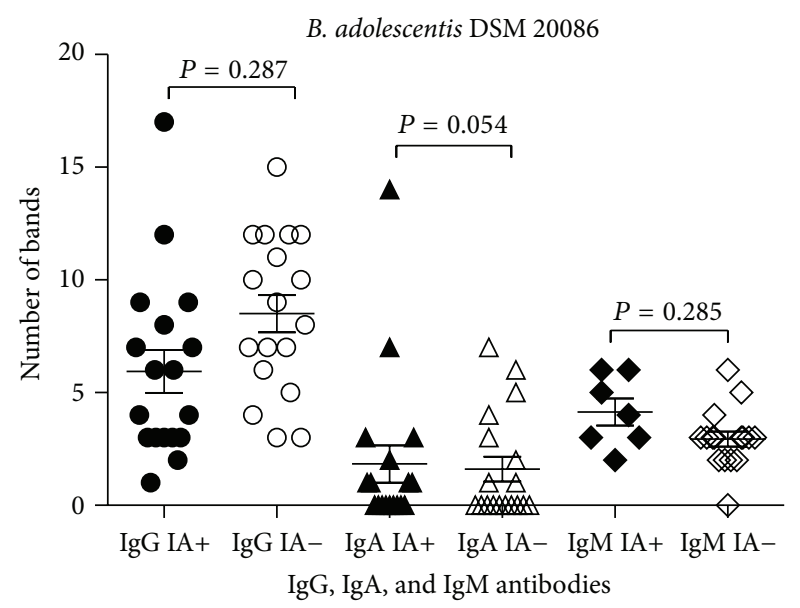

FIGURE 2: IgG, IgA, and IgM reactivity to B. adolescentis DSM 20086 proteins among IA-positive and IA-negative individuals.

B. longum DSM 20088

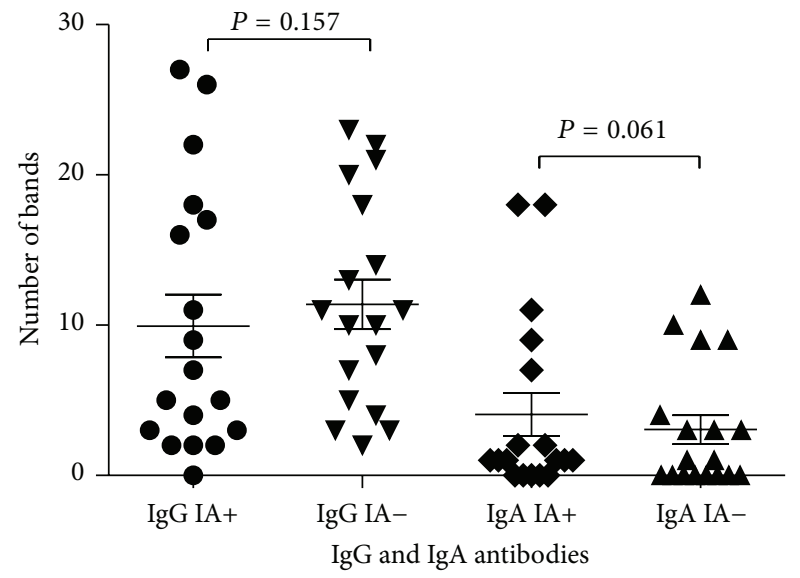

Figure 3: IgA and IgG reactivity against B. longum DSM 20088 proteins among IA-positive and IA-negative individuals.

$20088(N=57$; Table 1$)$. The average number of IgGreactive proteins in assays with $B$. adolescentis DSM 20083, $B$. adolescentis DSM 20086, and B. longum DSM 20088 strains was not significantly different between IA-positive children and IA-negative subjects (Figures 1-3).

3.3. IgA Reactivity against B. adolescentis and B. longum Proteins. IgA bound to protein antigens in the molecular weight ranging from $7 \mathrm{kDa}$ to $104 \mathrm{kDa}$ (Table 1). Similar to the IgG antibody results, more B. longum DSM 20088 proteins were recognized by IgA than any other tested bacteria. The average number of $B$. adolescentis DSM 20083 proteins bound by IgA was lower than the number of proteins bound from other strains. There was a significant difference in the number of proteins reactive to antibodies between the 2 groups of children: $1.9 \pm 2.6$ reactive protein bands in IA-positive infants and $1.2 \pm 1.2$ reactive protein bands in IA-negative children $(P<0.003$; Figure 1). Also in tests with Bifidobacterium strains the average number of reacting antigenic proteins 
TABLE 1: Molecular weight ranges of proteins reacting with IgA and IgG antibodies and the number of detectable antigenic proteins present in different bacterial homogenates.

\begin{tabular}{|c|c|c|c|c|}
\hline & \multicolumn{2}{|c|}{ Antigenic protein $\mathrm{MW}$ ranges } & \multicolumn{2}{|c|}{ Number of reactive antigenic proteins } \\
\hline & $\operatorname{IgG}$ & $\operatorname{IgA}$ & IgG & $\operatorname{IgA}$ \\
\hline L. rhamnosus GG & $11-86 \mathrm{kDa}$ & n.t. ${ }^{*}$ & 25 & n.t. ${ }^{*}$ \\
\hline B. adolescentis DSM 20083 & $7-80 \mathrm{kDa}$ & $7-72 \mathrm{kDa}$ & 31 & 20 \\
\hline B. adolescentis DSM 20086 & $10-131 \mathrm{kDa}$ & $10-92 \mathrm{kDa}$ & 36 & 24 \\
\hline B. longum DSM 20088 & $10-127 \mathrm{kDa}$ & $10-104 \mathrm{kDa}$ & 57 & 44 \\
\hline
\end{tabular}

${ }^{*}$ n.t.: not tested.

TABLE 2: The number of children in different age groups with serum IgG reactivity to different L. rhamnosus GG proteins. The age period when significantly more $(P<0.05)$ antibodies against bacterial proteins were observed compared to the 3-month age group is shown in bold.

\begin{tabular}{|c|c|c|c|c|c|c|c|c|}
\hline \multirow{2}{*}{$\begin{array}{l}\text { L. rhamnosus GG } \\
\text { antigenic proteins }\end{array}$} & \multicolumn{2}{|c|}{ 3-month } & \multicolumn{2}{|c|}{ 6-month } & \multicolumn{2}{|c|}{ 12-month } & \multicolumn{2}{|c|}{ 24-month } \\
\hline & $\begin{array}{l}\text { IA-positive } \\
(N=18)\end{array}$ & $\begin{array}{l}\text { IA-negative } \\
\qquad(N=18)\end{array}$ & $\begin{array}{l}\text { IA-positive } \\
\qquad(N=19)\end{array}$ & $\begin{array}{l}\text { IA-negative } \\
\qquad(N=19)\end{array}$ & $\begin{array}{l}\text { IA-positive } \\
\qquad(N=18)\end{array}$ & $\begin{array}{l}\text { IA-negative } \\
\qquad(N=18)\end{array}$ & $\begin{array}{l}\text { IA-positive } \\
\qquad(N=15)\end{array}$ & $\begin{array}{l}\text { IA-negative } \\
\qquad(N=18)\end{array}$ \\
\hline $65 \mathrm{kDa}$ & $8(44)$ & $14(78)$ & $14(74)^{*}$ & $17(89)$ & $17(94)$ & $17(94)$ & $15(100)$ & $17(94)$ \\
\hline $58 \mathrm{kDa}$ & $8(44)$ & $12(67)$ & $18(95)$ & $19(100)$ & $17(94)$ & $17(94)$ & 15 (100) & $18(100)$ \\
\hline $49 \mathrm{kDa}$ & $2(11)$ & $2(11)$ & $2(10)$ & $4(21)$ & $6(33)$ & $8(44)$ & $4(27)$ & $7(39)$ \\
\hline $47 \mathrm{kDa}$ & $4(22)$ & $4(22)$ & $8(42)$ & $7(37)$ & $9(50)$ & $12(67)$ & $7(47)$ & $8(44)$ \\
\hline $45 \mathrm{kDa}$ & $9(50)$ & $11(61)$ & $11(58)$ & $11(58)$ & $16(89)$ & $14(78)$ & 15 (100) & $18(100)$ \\
\hline $42 \mathrm{kDa}$ & $3(17)$ & $4(22)$ & $5(26)$ & $7(37)$ & $9(50)$ & 7 (39) & $8(53)$ & $9(50)$ \\
\hline $38 \mathrm{kDa}$ & $1(5)$ & $3(17)$ & $2(10)$ & $2(10)$ & $5(28)$ & $5(28)$ & $8(53)$ & $8(44)$ \\
\hline $31 \mathrm{kDa}$ & $13(72)$ & $9(50)$ & $14(74)$ & $11(58)$ & $17(94)$ & $17(94)$ & $15(100)$ & $16(89)$ \\
\hline $27 \mathrm{kDa}$ & $0(0)$ & $4(22)$ & $1(5)$ & $2(10)$ & $2(11)$ & $2(11)$ & $5(33)$ & $6(33)$ \\
\hline
\end{tabular}

${ }^{*}$ Number and $\%$ (in brackets) of children with positive reactions to this protein.

tended to be at a higher frequency in the IA-positive group compared to the IA-negative group (Figures 2 and 3).

3.4. IgM Reactivity to B. adolescentis Proteins. IgM bound to bacterial proteins in the molecular weight ranging from $13 \mathrm{kDa}$ to $84 \mathrm{kDa}$. The average number of $\operatorname{IgM}$ reacting protein bands in both assays either with B. adolescentis DSM 20083 or with B. adolescentis DSM 20086 was higher in IApositive than in IA-negative infants, but this difference was not statistically significant $(P=0.235$ and $P=0.285$, resp.; Figures 1 and 2).

\section{Discussion}

This study investigated the reactivity of serum antibodies against the probiotic strain L. rhamnosus GG and selected natural Bifidobacterium spp. proteins in children 3, 6, 12, and 24 months of age using an immunoblot assay developed previously by our group [20]. L. rhamnosus GG is included into the most commonly used dairy products in Finland, whereas all chosen Bifidobacterium strains, B. adolescentis DSM 20083, B. adolescentis DSM 20086, and B. longum DSM 20088, are usual inhabitants of the intestinal microbiota. The colonization of newborns with microbes begins during delivery and by 2 months of age $91 \%$ of infants are colonized with B. longum, $75 \%$ with B. adolescentis, and $57 \%$ with Lactobacilli group I (L. rhamnosus, L. casei, and L. paracasei) [10]. A shift in colonization with $B$. adolescentis strains towards earlier life has been demonstrated recently [14] and this has also been observed at the age of 5 years [13].

The population studied here was obtained from the Finnish DIPP Study and divided into 2 groups based on the development of diabetes-associated autoantibodies and T1D over a 10-year followup. Immunoblot analyses of bacterial lysates demonstrated a substantial increase in the frequency of IgG antibody reactivity to L. rhamnosus GG proteins between 6 and 12 months of age, showing that the most conspicuous increase in antibody production occurred before the age of 12 months. In spite of these age-dependent changes, reactions against $L$. rhamnosus GG proteins were seen in IA-positive and IA-negative subjects at a similar frequency. This result indicated that IgG antibodies reactive to probiotic strain L. rhamnosus GG proteins were not suggestive of progression toward $\beta$-cell autoimmunity or development of T1D in children. The most important observation made from immunoblot assays testing antibody reactivity to L. rhamnosus GG proteins was the age-related dynamics associated with the development of circulating antibodies to microbial proteins. This emphasized how important it was to carry out these analyses using Bifidobacterium spp. proteins since these organisms are known to colonize the infant's gut early in life. We assessed binding to different antigenic proteins from $B$. adolescentis DSM 20083, B. adolescentis DSM 20086, and $B$. longum DSM 20088 by IgG, IgA, and IgM class antibodies and observed that IgA bound significantly more B. adolescentis DSM 20083 strain antigens in children who developed islet 
autoimmunity and T1D later in life. At the same time we could not find any significant differences between the two groups of children in the frequencies of IgG or IgA antibodies against other bifidobacteria strains. It is noteworthy that we found that $B$. longum proteins were recognized by IgG and IgA antibodies to a substantially higher extent compared to other bacteria studied. This phenomenon may indicate a stronger stimulation of the infant's immune system by $B$. longum protein antigens.

Some of the immunoreactive bands detected may be due to cross-reactive antibodies that developed in response to bacterial antigens from species not used in this study. It is however very difficult to make this distinction since we presently have no tools (monoclonal antibodies) to discriminate between strain-specific reactivity and cross-reactivity. Regardless, it was clear that differences in the development of IgA antibodies with reactivity against $B$. adolescentis DSM 20083 (ATCC 15703) antigens were present independent of the mechanism involved. It is of particular importance to note that differences between the 2 groups were associated with reactivity by IgA but not IgG or IgM class antibodies. $\operatorname{IgA}$ with reactivity against commensal intestinal microbes can develop as a consequence of colonization with high numbers of organisms at the mucosal surface [22]. It has been shown that oral administration of the probiotic mixture VSL\#3 that includes 8 different probiotic strains (including 3 bifidobacteria strains) prevented the development of autoimmune diabetes in nonobese diabetic mice [23]. Different bifidobacteria strains have clearly been shown to have variable influences on immune responses [23, 24]. The species of $B$. adolescentis most commonly isolated from allergic children has been shown to more effectively trigger the production of proinflammatory cytokines compared to other strains of bifidobacteria $[25,26]$ supporting our results that demonstrated differences between children with and without signs of $\beta$-cell autoimmunity with regard to reactivity to $B$. adolescentis strain 20083 antigens which might impact T1D development. Whether these differences are in some way linked to differences in the microbiome needs further studies $[27,28]$.

In conclusion, during the first year of life the immune system starts to produce antibodies which recognize antigens produced by organisms comprising the normal microbiota. Although some of these proteins may contain common antigenic epitopes present on proteins produced by various bacteria, our current study showed that differences in antibody reactivities could be found even between the same species of $B$. adolescentis. These differences might reflect a propensity for developing T1D confirming recent findings regarding differences in the gut microbiome between children affected and unaffected by T1D. Further studies will be needed to verify how the presence of this particular B. adolescentis DSM 20083 strain in the intestine of children is involved in predisposing individuals to developing $\beta$-cell autoimmunity and T1D.

\section{Conflict of Interests}

The authors declare that there is no conflict of interests regarding the publication of this paper.

\section{Acknowledgments}

This work was supported by Grants from Estonian Ministry of Education and Research (SF0180035 and SF0180132) and the Sigrid Juselius Foundation. The DIPP study was supported by Special Public Grants for Medical Research at Oulu, Tampere, and Turku University Hospitals, the Academy of Finland, the Juvenile Diabetes Research Foundation International, the Novo-Nordisk Foundation, and European Union Biomed 2. European Union Regional Developmental Fund's support to the Centre for Translational Medicine at the University of Tartu is gratefully appreciated.

\section{References}

[1] C. Taplin and J. Barker, "Autoantibodies in type 1 diabetes," Autoimmunity, vol. 41, no. 1, pp. 11-18, 2008.

[2] K. Vehik, M. J. Haller, C. A. Beam et al., "Islet autoantibody seroconversion in the DPT-1 study: justification for repeat screening throughout childhood," Diabetes Care, vol. 34, no. 2, pp. 358$362,2011$.

[3] M. Knip, S. Korhonen, P. Kulmala et al., "Prediction of type 1 diabetes in the general population," Diabetes Care, vol. 33, no. 6, pp. 1206-1212, 2010.

[4] K. Salminen, K. Sadeharju, M. Lönnrot et al., "Enterovirus infections are associated with the induction of $\beta$-cell autoimmunity in a prospective birth cohort study," Journal of Medical Virology, vol. 69, no. 1, pp. 91-98, 2003.

[5] J. Wahlberg, J. Fredriksson, E. Nikolic et al., "Environmental factors related to the induction of beta-cell autoantibodies in 1-yr-old healthy children," Pediatric Diabetes, vol. 6, no. 4, pp. 199-205, 2005.

[6] A. T. Borchers, R. Uibo, and M. E. Gershwin, "The geoepidemiology of type 1 diabetes," Autoimmunity Reviews, vol. 9, no. 5, pp. A355-A365, 2010.

[7] E. J. Schiffrin and S. Blum, "Interactions between the micrbiota and the intestinal mucosa," European Journal of Clinical Nutrition, vol. 56, pp. 560-564, 2002.

[8] F. He, A. C. Ouwehand, E. Isolauri, H. Hashimoto, Y. Benno, and S. Salminen, "Comparison of mucosal adhesion and species identification of bifidobacteria isolated from healthy and allergic infants," FEMS Immunology and Medical Microbiology, vol. 30, no. 1, pp. 43-47, 2001.

[9] E. Furrie, "Probiotics and allergy," Proceedings of the Nutrition Society, vol. 64, no. 4, pp. 465-469, 2005.

[10] Y. M. Sjögren, S. Tomicic, A. Lundberg et al., "Influence of early gut microbiota on the maturation of childhood mucosal and systemic immune responses: gut microbiota and immune responses," Clinical and Experimental Allergy, vol. 39, no. 12, pp. 1842-1851, 2009.

[11] G. Hörmannsperger and D. Haller, "Molecular crosstalk of probiotic bacteria with the intestinal immune system: clinical relevance in the context of inflammatory bowel disease," International Journal of Medical Microbiology, vol. 300, no. 1, pp. 6373, 2010.

[12] A. C. Ouwehand, E. Isolauri, F. He, H. Hashimoto, Y. Benno, and S. Salminen, "Differences in Bifidobacterium flora composition in allergic and healthy infants," Journal of Allergy and Clinical Immunology, vol. 108, no. 1, pp. 144-145, 2001.

[13] J. Štšepetova, E. Sepp, K. Julge, E. Vaughan, M. Mikelsaar, and W. M. De Vos, "Molecularly assessed shifts of Bifidobacterium 
ssp. and less diverse microbial communities are characteristic of 5-year-old allergic children," FEMS Immunology and Medical Microbiology, vol. 51, no. 2, pp. 260-269, 2007.

[14] Y. M. Sjögren, M. C. Jenmalm, M. F. Böttcher, B. Björkstén, and E. Sverremark-Ekström, "Altered early infant gut microbiota in children developing allergy up to 5 years of age," Clinical and Experimental Allergy, vol. 39, no. 4, pp. 518-526, 2009.

[15] N. Takahashi, H. Kitazawa, N. Iwabuchi et al., "Immunostimulatory oligodeoxynucleotide from Bifidobacterium longum suppresses Th2 immune responses in a murine model," Clinical and Experimental Immunology, vol. 145, no. 1, pp. 130-138, 2006.

[16] M. Medina, E. Izquierdo, S. Ennahar, and Y. Sanz, "Differential immunomodulatory properties of Bifidobacterium logum strains: relevance to probiotic selection and clinical applications," Clinical and Experimental Immunology, vol. 150, no. 3, pp. 531-538, 2007.

[17] A. L. Hart, K. Lammers, P. Brigidi et al., "Modulation of human dendritic cell phenotype and function by probiotic bacteria," Gut, vol. 53, no. 11, pp. 1602-1609, 2004.

[18] M. Kalliomäki, S. Salminen, H. Arvilommi, P. Kero, P. Koskinen, and E. Isolauri, "Probiotics in primary prevention of atopic disease: a randomised placebo-controlled trial," Lancet, vol. 357, no. 9262, pp. 1076-1079, 2001.

[19] F. Yan, H. Cao, T. L. Cover et al., "Colon-specific delivery of a probiotic-derived soluble protein ameliorates intestinal inflammation in mice through an EGFR-dependent mechanism," Journal of Clinical Investigation, vol. 121, no. 6, pp. 2242-2253, 2011.

[20] A.-L. Prangli, M. Utt, I. Talja et al., "Antigenic proteins of Lactobacillus acidophilus that are recognised by serum IgG antibodies in children with type 1 diabetes and coeliac disease," Pediatric Allergy and Immunology, vol. 21, no. 4, pp. e772-e779, 2010.

[21] I. Nilsson, I. Kornilovs'ka, S. Lindgren, Å. Ljungh, and T. Wadström, "Increased prevalence of seropositivity for nongastric Helicobacter species in patients with autoimmune liver disease," Journal of Medical Microbiology, vol. 52, no. 11, pp. 949953, 2003.

[22] A. J. Macpherson, M. B. Geuking, E. Slack, S. Hapfelmeier, and K. D. McCoy, "The habitat, double life, citizenship, and forgetfulness of IgA," Immunological Reviews, vol. 245, no. 1, pp. 132146, 2012.

[23] A. Aumeunier, F. Grela, A. Ramadan et al., "Systemic toll-like receptor stimulation suppresses experimental allergic asthma and autoimmune diabetes in NOD mice," PLoS ONE, vol. 5, no. 7, Article ID e11484, 2010.

[24] P. López, M. Gueimonde, A. Margolles, and A. Suárez, “Distinct Bifidobacterium strains drive different immune responses in vitro," International Journal of Food Microbiology, vol. 138, no. 1-2, pp. 157-165, 2010.

[25] D. R. Kramer, R. M. Sutherland, S. Bao, and A. J. Husband, "Cytokine mediated effects in mucosal immunity," Immunology and Cell Biology, vol. 73, no. 5, pp. 389-396, 1995.

[26] F. He, H. Morita, H. Hashimoto et al., "Intestinal Bifidobacterium species induce varying cytokine production," Journal of Allergy and Clinical Immunology, vol. 109, no. 6, pp. 1035-1036, 2002.

[27] A. Giongo, K. A. Gano, D. B. Crabb et al., "Toward defining the autoimmune microbiome for type 1 diabetes," ISME Journal, vol. 5, no. 1, pp. 82-91, 2011.

[28] C. T. Brown, A. G. Davis-Richardson, A. Giongo et al., "Gut microbiome metagenomics analysis suggests a functional model for the development of autoimmunity for type 1 diabetes," PLoS ONE, vol. 6, no. 10, Article ID e25792, 2011. 


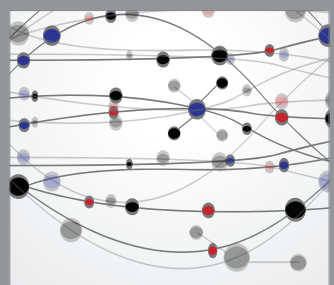

The Scientific World Journal
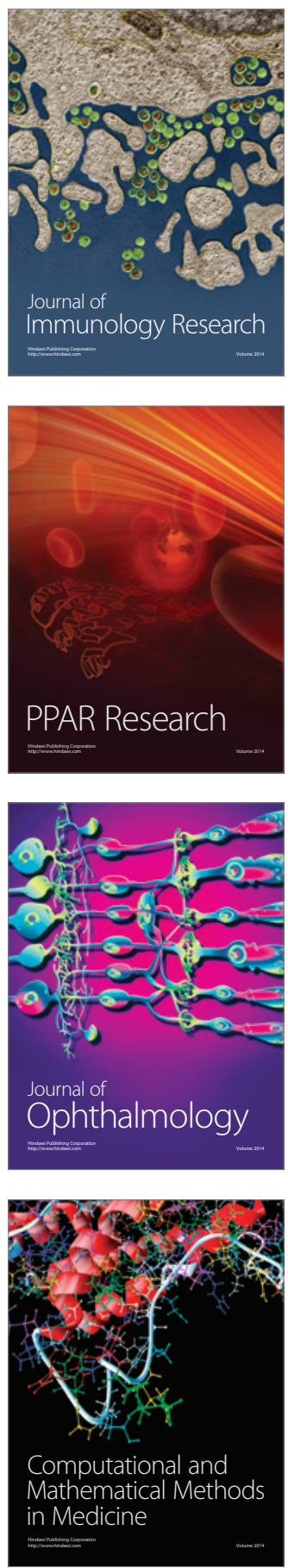

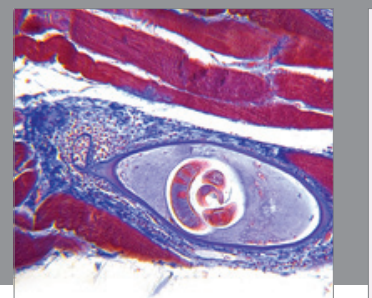

Gastroenterology

Research and Practice
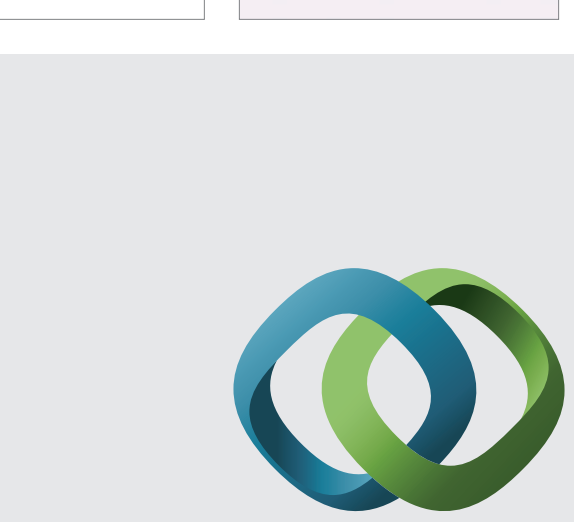

\section{Hindawi}

Submit your manuscripts at

http://www.hindawi.com
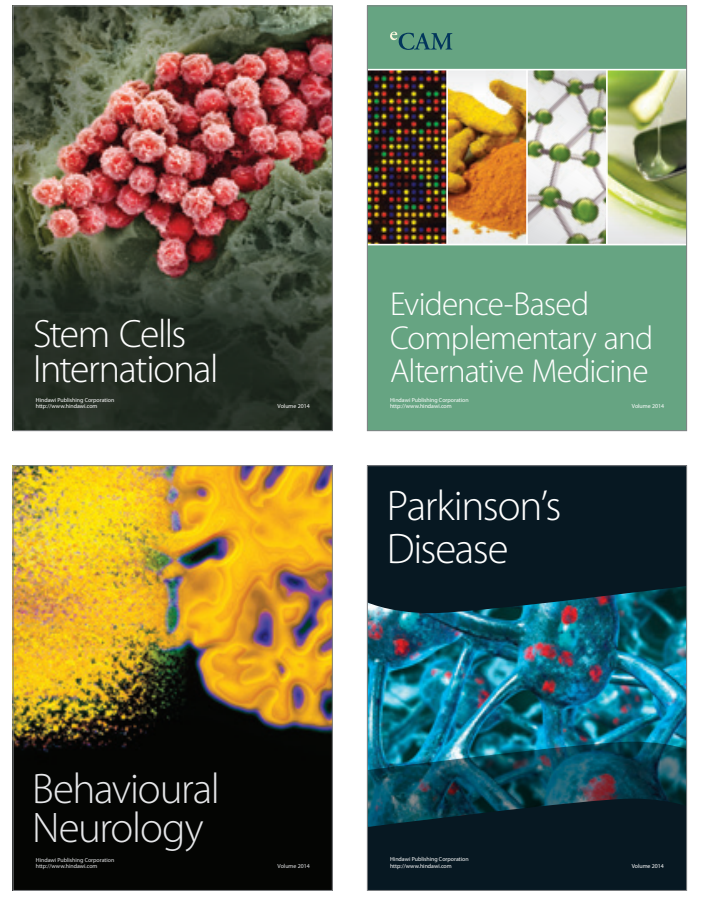
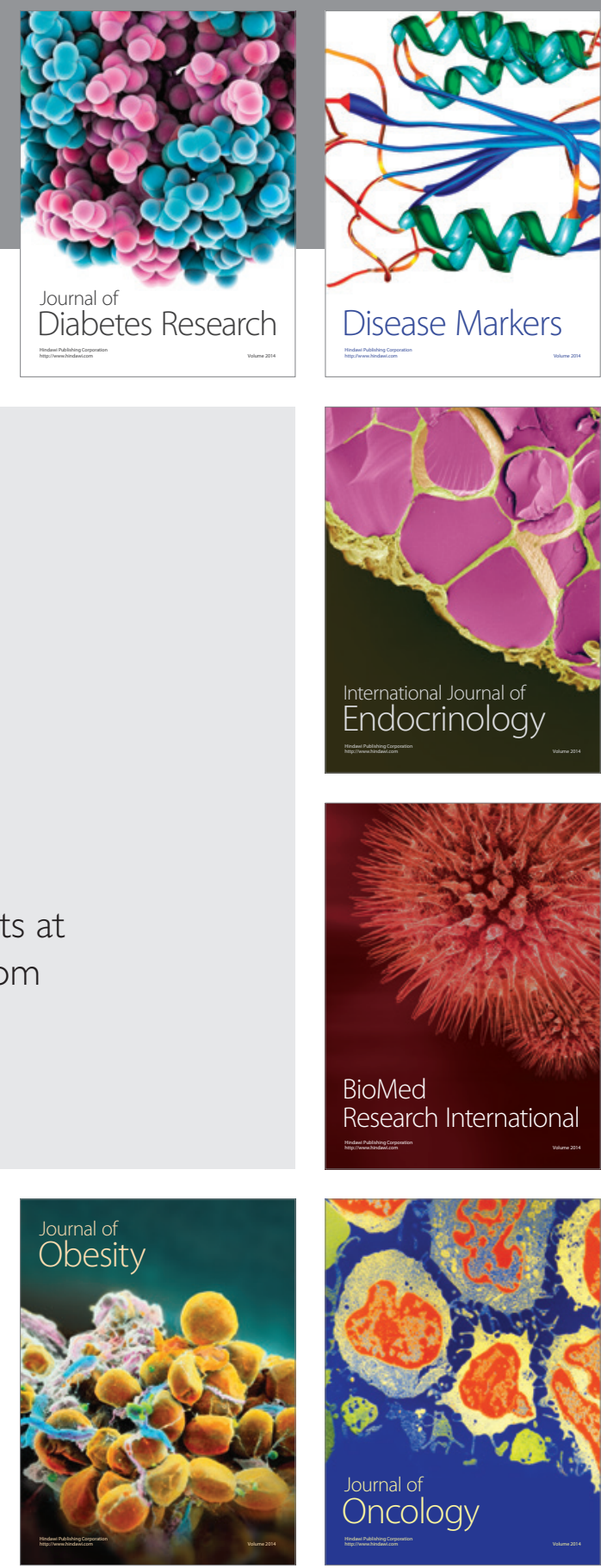

Disease Markers
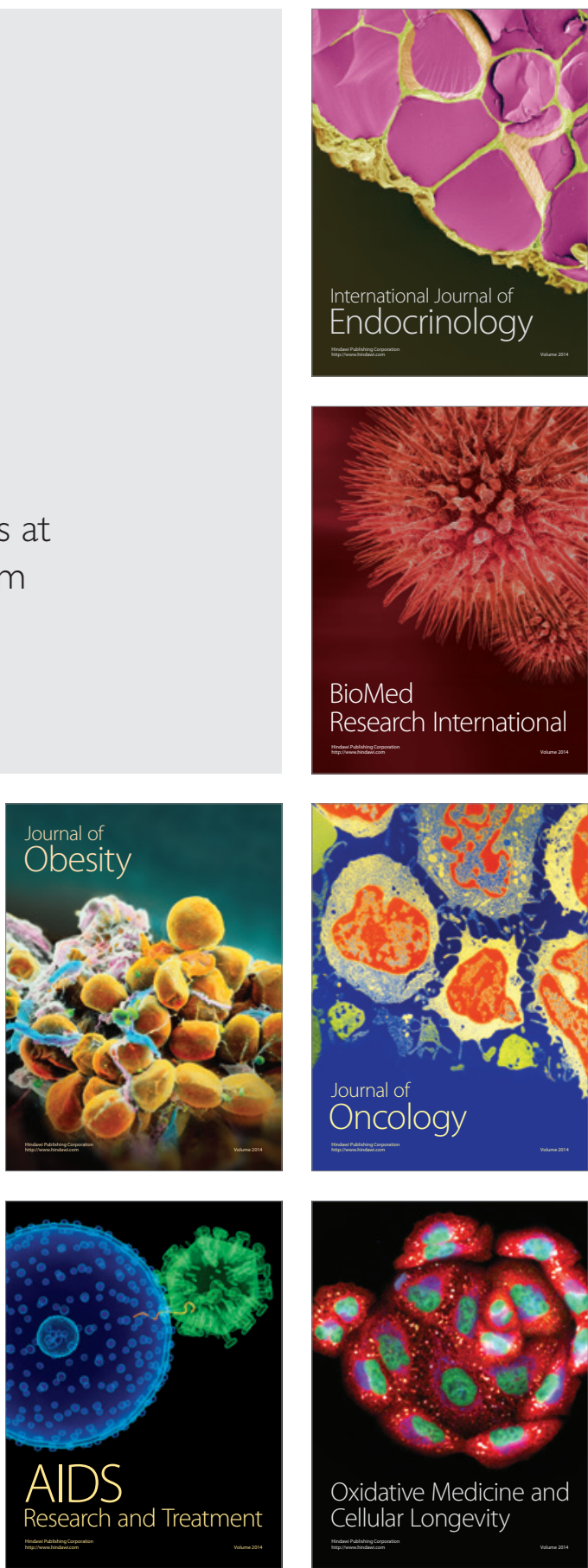